\title{
STUDI KASUS PERBANDINGAN ANALISIS PENURUNAN AKIBAT TIMBUNAN, DI TANGERANG, BANTEN
}

\author{
Fachry Ibrahim ${ }^{1}$, Gregorius Sandjaja S. ${ }^{2}$ dan Aksan Kawanda ${ }^{3}$ \\ ${ }^{1}$ Program Studi Sarjana Teknik Sipil, Universitas Tarumanagara, Jl. Letjen S. Parman No.1 Jakarta \\ Email: fchryIbrahim58@gmail.com \\ ${ }^{2}$ Program Studi Sarjana Teknik Sipil, Universitas Tarumanagara, Jl. Letjen S. Parman No.1 Jakarta \\ Email: gregoriuss@ft.untar.ac.id \\ ${ }^{3}$ Program Studi Sarjana Teknik Sipil, Universitas Tarumanagara, Jl. Letjen S. Parman No.1 Jakarta \\ Email: akawanda@geotech-indonesia.com
}

\begin{abstract}
ABSTRAK
Permasalahan yang sering terjadi dalam konstruksi pembangunan jalan adalah kondisi tanah dasar pada permukaan tanah yang lunak. Apabila tidak dilakukan perbaikan tanah terlebih dahulu pada jenis tanah ini, maka tanah dasar akan mengalami penurunan yang relatif besar, maka dari itu penimbunan yang dilakukan pada tanah lunak akan mengalami penurunan konsolidasi. Konsolidasi merupakan fenomena dalam mekanika tanah yang sering menimbulkan permasalahan geoteknik yang terjadi pada waktu yang lama. perbaikan tanah dilakukan dengan pemasangan PVD yang diberi beban untuk mempercepat proses konsolidasi demi tercapainya penurunan akhir. Studi ini bertujuan untuk mengetahui penurunan konsolidasi dengan metode Terzaghi, program FEM (finite element method), dan metode Asaoka, lalu membandingkan hasil dari penurunan konsolidasi ketiga metode dengan aktual. Prediksi penurunan konsolidasi teori Terzaghi, memberikan hasil yang lebih besar dari penurunan aktual. Pada prediksi penurunan tanah dengan FEM, analisis terhadap penurunan dan waktu sangat bergantung terhadap parameter, sehingga metode ini tidak memberikan hasil yang cukup baik jika tidak berdasarkan parameter pada tanah aslinya. Estimasi hasil dari Asaoka dapat diperoleh nilai penurunan akhir yang lebih mendekati penurunan aktual lapangan. Nilai penurunan ini diperoleh berdasarkan pengamatan penurunan awal di lapangan, sehingga hasil analisis akan lebih sesuai.
\end{abstract}

Kata kunci: Penurunan konsolidasi, teori Terzaghi, finite element method, teori Asaoka.

\section{PENDAHULUAN}

Tanah adalah himpunan mineral, bahan organik, dan endapan-endapan yang relatif lepas, yang terletak di atas batuan dasar. Ikatan antara butiran yang relatif lemah dapat disebabkan oleh karbonat, zat organik, atau oksidaoksida yang mengendap diantara partikel-partikel ruang yang berisi air, udara ataupun keduanya. Pada Kondisi tanah dasar dalam konstruksi pembangunan jalan merupakan permasalahan yang sering terjadi, terlebih pada permukaan tanah lunak. Apabila tidak dilakukan perbaikan tanah terlebih dahulu pada jenis tanah ini, maka jalan yang dibangun akan mengalami penurunan yang relatif besar pada tanah dasar, maka dari itu penimbunan yang dilakukan pada tanah lunak akan mengalami penurunan konsolidasi.

Konsolidasi merupakan fenomena dalam mekanika tanah yang sering menimbulkan permasalahan geoteknik yang terjadi pada waktu yang lama. Konsolidasi terjadi akibat berkurangnya volume atau berkurangnya rongga pori dari tanah jenuh yang berpermeabilitas rendah akibat beban statis yang bekerja dalam periode tertentu, di mana prosesnya dipengaruhi oleh kecepatan terperasnya air pori keluar dari rongga tanahnya. Maka dari itu diperlukan perbaikan tanah dengan dilakukan pemasangan PVD (Prefabricated Vertical Drain) yang diberi beban untuk mempercepat proses konsolidasi demi tercapainya penurunan akhir.

Jika lapisan tanah mengalami pembebanan maka lapisan tanah akan mengalami regangan atau penurunan. Regangan yang terjadi dalam tanah di sebabkan oleh berubahnya susunan tanah oleh pengurangan rongga pori/air didalam tanah. Jumlah dari regangan sepanjang kedalaman lapisan merupakan penurunan total tanahnya. Penurunan akibat beban adalah jumlah total dari penurunan segera (immediate settlement) dan penurunan konsolidasi (consolidation settlement).

\section{Studi parameter tanah}

Analisis parameter tanah yang dilakukan adalah dengan mengelompokan tanah sesuai karakteristik tanah, penentuan parameter tanah dari beberapa data tanah dengan cara korelasi parameter tanah yang tidak diketahui. 


\section{Korelasi parameter tanah}

Berat volume tanah jenuh didapatkan berdasarkan nilai N-SPT dengan merujuk pada Tabel 1 dan berat volume tanah kering dengan merujuk pada Tabel 2.

Tabel 1. Korelasi Empiris Antara Nilai N-SPT dan Berat Volume Tanah Jenuh $\left(\gamma_{\text {sat }}\right)$ untuk Tanah Kohesif (Lambe \& Whitman 1969, dari Terzaghi \& Peck 1948)

\begin{tabular}{cccc}
\hline N-SPT & Konsistensi & $q_{u}\left(\mathrm{kN} / \mathrm{m}^{3}\right)$ & $\gamma_{s a t}\left(\mathrm{kN} / \mathrm{m}^{3}\right)$ \\
\hline$<2$ & Very Soft & $<25$ & $16-19$ \\
\hline $2-4$ & Soft & $25-50$ & $16-19$ \\
\hline $4-8$ & Medium & $50-100$ & $17-20$ \\
\hline $8-15$ & Stiff & $100-200$ & $19-22$ \\
\hline $15-30$ & Very Stiff & $200-400$ & $19-22$ \\
\hline$>30$ & Hard & $>400$ & $19-22$ \\
\hline
\end{tabular}

Tabel 2. Korelasi Empiris antara Berat Volume Tanah Jenuh dan Berat Volume Tanah Kering (Budhu, 2000)

\begin{tabular}{ccc} 
Jenis tanah & $\gamma_{\text {sat }}\left(\mathrm{kN} / \mathrm{m}^{3}\right)$ & $\gamma_{\text {dry }}\left(\mathrm{kN} / \mathrm{m}^{3}\right)$ \\
\hline Kerikil & $20-22$ & $15-17$ \\
\hline Pasir & $18-20$ & $13-16$ \\
\hline Lanau & $18-20$ & $14-18$ \\
\hline Lempung & $16-20$ & $14-21$ \\
\hline
\end{tabular}

Angka pori $(e)$ didapatkan berdasarkan hubungan antara angka pori dan porositas dengan persamaan 1:

$$
e=\frac{n}{1-n}
$$

Berat spesifik atau berat jenis (specific gravity) $\left(G_{s}\right)$ didapatkan berdasarkan persamaan 2:

$$
\gamma_{\text {sat }}=\frac{\gamma_{w}\left(G_{S}+\mathrm{e}\right)}{1+e}
$$

Berat volume tanah basah atau lembab $\left(\gamma_{b}\right)$ dapat dinyatakan berdasarkan persamaan 3:

$$
\gamma_{b}=\frac{G_{s} \gamma_{w}(1+W)}{1+e}
$$

$S_{u}$ atau $C_{u}$ yang merupakan kuat geser undrained menurut Bowles (1988) dapat ditentukan berdasarkan persamaan 4:

$$
S_{u}=C_{u}=6 \times \mathrm{N}-\mathrm{SPT}\left(\mathrm{kN} / \mathrm{m}^{3}\right)
$$

\section{Beban terbagi rata berbentuk trapesium memanjang tak hingga}

$\Delta \sigma$ merupakan tambahan tegangan akibat pengaruh beban timbunan yang ditinjau di tengah-tengah lapisan. Menurut Braja M. Das (1986), dalam bukunya "Principles of Foundation Engineering, Second Edition" diagram tegangan tanah akibat timbunan adalah sebagai persamaan berikut:

$$
\Delta \sigma=\frac{q_{o}}{\pi}\left[\left(\frac{B 1+B 2}{B 2}\right)(\alpha 1+\alpha 2)-\frac{B 1}{B 2} \alpha 2\right]
$$

dengan $\Delta \sigma=$ tegangan akibat beban timbunan yang ditinjau di tengah lapisan, $q_{0}=$ beban timbunan $\left(\gamma_{\text {timbunan }} \mathrm{x}\right.$ $\left.H_{\text {timbunan }}\right), B 1=$ setengah lebar timbunan, $B 2=$ panjang proyeksi horizontal kemiringan timbunan, $\alpha 1=$ $\tan ^{-1}\left(\frac{B 1+B 2}{Z}\right)-\tan ^{-1}\left(\frac{B 1}{Z}\right), \alpha 2=\tan ^{-1}\left(\frac{B 1}{Z}\right)$ dan $Z=$ kedalaman yang ditinjau 


\section{Teori Terzaghi}

Teori konsolidasi satu dimensi Terzaghi telah lama dipergunakan untuk memprediksi penurunan serta waktu konsolidasi. Teori ini sudah sangat lazim dipergunakan dan dianggap dapat menjelaskan penurunan akibat kompresi dan drainase satu dimensi pada tanah secara baik.

\section{Fase pemampatan konsolidasi primer (primary consolidation)}

Pemampatan konsolidasi primer merupakan proses keluarnya air dan udara dari dalam tanah akibat bekerjanya beban luar yang dipengaruhi oleh waktu. Besar pemampatan konsolidasi primer pada lapisan tanah lunak setebal $H$ dapat dihitung dengan menggunakan persamaan (Das, 1985).

Untuk lempung normally consolidated:

$$
S c=C_{C} \frac{H}{1+e_{0}} \log \left(\frac{\sigma_{0}^{\prime}+\Delta_{p}}{\sigma_{0}^{\prime}}\right)
$$

Untuk lempung overconsolidated:

$$
\begin{aligned}
& \text { (a) Bila } \sigma_{0}^{\prime}+\Delta_{p}<\sigma_{c}^{\prime}: \\
& S c=C_{S} \frac{H}{1+e_{0}} \log \left(\frac{\sigma_{0}^{\prime}+\Delta_{p}}{\sigma_{0}^{\prime}}\right) \\
& \text { (b) Bila } \sigma_{0}^{\prime}+\Delta_{p}>\sigma_{c}^{\prime}: \\
& S c=C_{S} \frac{H}{1+e_{0}} \log \left(\frac{\sigma_{c}^{\prime}}{\sigma_{0}^{\prime}}\right)+C_{C} \frac{H i}{1+e_{0}} \log \left(\frac{\sigma_{0}^{\prime}+\Delta_{p}}{\sigma_{c}^{\prime}}\right)
\end{aligned}
$$

dengan $S c$ = besar pemampatan konsolidasi, $C_{c}=$ indeks pemampatan tanah, $C_{s}=$ indeks pemampatan kembali, $H=$ tebal lapisan tanah, $\sigma_{0}^{\prime}=$ tekanan overburden efektif, $\sigma_{c}^{\prime}=$ tekanan prakonsolidasi dan $\Delta_{p}=$ tambahan tegangan

\section{Analisis dan pemodelan penurunan tanah dengan FEM (finite element method)}

Analisis dan prediksi penurunan konsolidasi tanah dapat dilakukan dengan FEM. Program pemodelan tanah yang menggunakan dasar teori metode elemen hingga bertujuan untuk memperoleh hasil desain perhitungan yang dibutuhkan dengan menginput parameter-parameter tanah dan elemen lain yang berperan dalam pekerjaan konstruksi.

Nilai parameter tanah yang digunakan dalam pemodelan FEM diperoleh dari data laboratorium maupun dari referensi korelasi parameter berdasarkan tipe tanah, berikut langkah-langkah pada analisis dengan FEM:

1. Langkah input merupakan langkah awal untuk melakukan pemodelan kondisi geoteknik yang terdiri dari koordinat dimensi dan segala parameter tanah yang akan ditinjau.

2. Langkah kalkulasi merupakan langkah setelah pemodelan selesai dan langsung diperoleh berbagai model perhitungan sesuai tujuan Analisis.

3. Merupakan langkah akhir dengan mengeluarkan hasil akhir pada Analisis.

\section{Prosedur observasi Asaoka}

Pada prosedur observasi Asaoka, hubungan antara penurunan tanah dan waktu diturunkan melalui persamaan diferensial berdasarkan persamaan dasar konsolidasi (Mikasa, 1963), yaitu:

$$
\varepsilon_{v}=C_{v} \varepsilon_{z z}
$$

dengan $\varepsilon(t, z)=$ regangan vertikal (regangan volume), $t(\geq 0)=$ waktu, $z=$ kedalaman dari bagian atas lempung dan $C_{v}=$ koefisien konsolidasi

Persamaan dasar konsolidasi ini diturunkan menjadi persamaan diferensial linier biasa oleh Asaoka (1978) untuk mendapatkan persamaan yang dapat menentukan nilai penurunan pada interval waktu ke-j, yang dituliskan sebagai:

$$
\rho j=\frac{\beta_{0}}{1-\beta_{1}}-\left\{\frac{\beta_{0}}{1-\beta_{1}}-\rho_{0}\right\}\left(\beta_{1}\right)^{j}
$$

Dimana $\rho$ j adalah besarnya penurunan tanah pada waktu $t=t j$, dan koefisien $\beta_{0}$ dan $\beta_{s}(s=1,2, \ldots, n)$ adalah parameter yang tidak diketahui.

Pengukuran data penurunan tanah di lapangan dilakukan dengan menggunakan instrumen settlement plate. Untuk memperoleh prediksi penurunan akhir tanah, maka data-data penurunan ini harus dipilih, sehingga diperoleh nilai 
penurunan $\rho_{1}, \rho_{2}, \rho_{3}, \ldots \rho_{n}$ dengan interval waktu $\Delta_{t}$ yang konstan seperti dilihat pada Gambar 1. Kemudian nilai $\rho_{n}$ (sumbu-y) dan nilai $\rho_{n-1}$ (sumbu-x) diplot sehingga akan diperoleh titik-titik yang membentuk garis lurus, seperti ditunjukkan pada Gambar 2. $\beta_{0}$ adalah waktu titik plot pertama dari regresi linear $\rho_{n}$ dan $\rho_{n-1}$. Penurunan akhir $\left(\rho_{f}\right)$ adalah titik pertemuan antara garis $\rho_{n}=\rho_{n-1}$ (bersudut $45^{\circ}$ ) dengan trendline dari garis $\rho_{n}$ vs $\rho_{n-1}$ sebenarnya. Setelah diperoleh penurunan akhir $\left(\rho_{f}\right)$ maka dapat dicari nilai $\beta_{1}$ yang merupakan kemiringan dari garis $\rho_{n}$ vs $\rho_{n-1}$ sebenarnya, yang memberikan hubungan:

$$
\beta_{1}=\frac{\rho_{f}-\beta_{0}}{\rho_{f}}
$$

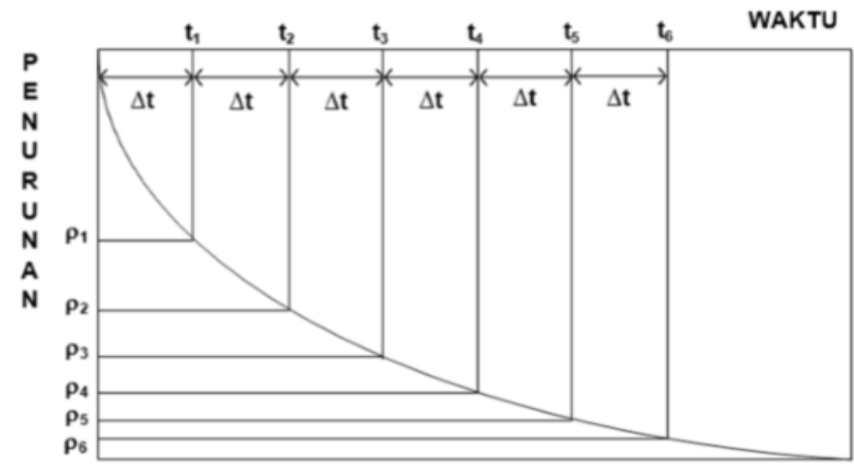

Gambar 1. Prosedur Analisis Data Monitoring Penurunan dengan Interval Waktu yang Konstan (Magnan and Deroy, 1980)

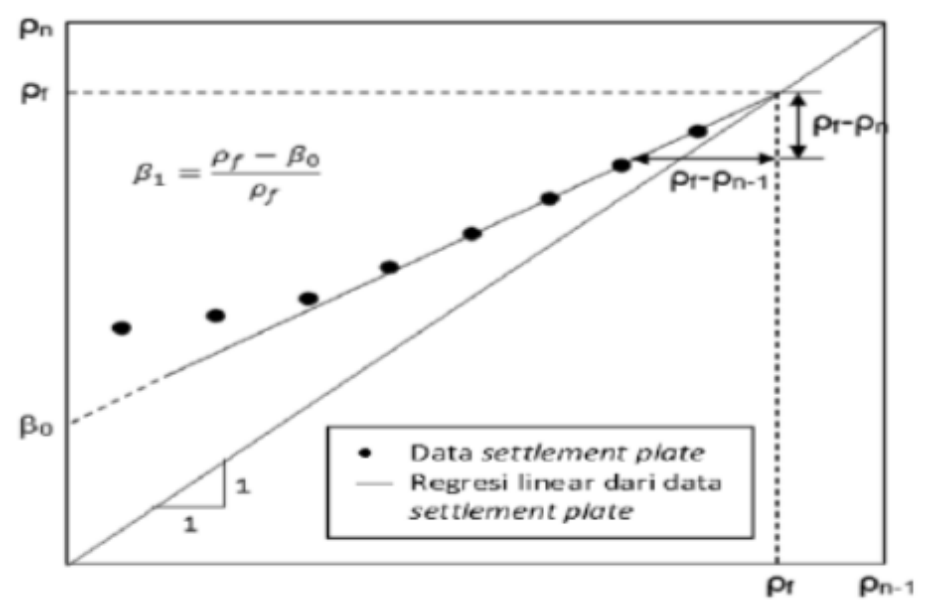

Gambar 2. Analisis Prediksi Penurunan Akhir Metode Asaoka (1978)

\section{Prefabricated vertical drains (PVD)}

Perbaikan tanah dengan metode konsolidasi secara umum dapat diartikan sebagai upaya yang dilakukan dengan menempatkan beban statis yang bersifat sementara (pre-loading) di atas lapisan tanah yang akan diperbaiki. Akibat beban tersebut, maka tanah akan mengalami pemadatan akibat tekanan dari beban sementara tersebut. Oleh karena proses konsolidasi membutuhkan waktu yang lama, maka biasanya metode konsolidasi tidak berdiri sendiri, melainkan dikombinasi dengan metode lain kombinasi dengan metode drainase (penyaluran air tanah ke permukaan tanah). 


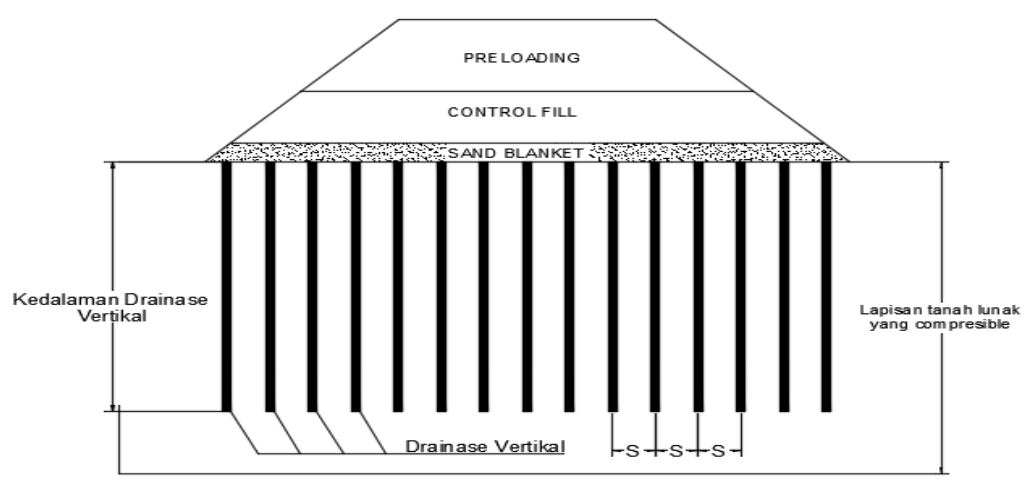

Gambar 3. Visualisasi penggunaan PVD

Pada perencanaan vertikal drain pada umumnya dihitung dengan menggunakan persamaan Barron (1948) yang relatif sederhana yaitu:

$$
t=\frac{D^{2}}{8 C_{r}} F_{n} \ln \frac{1}{1-U_{h}}
$$

dengan $t=$ waktu yang diperlukan untuk mencapai $U_{h}, U_{h}=$ derajat konsolidasi rata-rata akibat tekanan air pori kearah horizontal, $d_{e}=$ diameter pengaruh satu drain, $S=$ jarak as ke as vertikal drain, $C_{r}=$ koefisien konsolidasi akibat dispasi air pori kearah radial (horizontal), $F_{n}=\ln \left(D / d_{W}\right)-(3 / 4)$, faktor jarak vertikal drain, $d_{w}=(a+b) / 2$ $\approx 50 \mathrm{~mm}$ diameter sumur ekivalen vertikal drain, $a=$ lebar vertikal drain dan $b=$ ketebalan vertikal drain

Dengan memasukkan harga $t$ tertentu, dapat dicari harga $U_{h}$ pada lapisan tanah yang dipasang PVD. Selain konsolidasi akibat aliran air pori arah horizontal, juga terjadi konsolidasi akibat aliran air pori arah vertikal $U_{v}$. Harga $U_{v}$ dapat dicari dengan rumus sebagai berikut:

$$
T_{v}=\left(t \times C_{v}\right) /(H d r)^{2}
$$

dengan $T_{v}=$ faktor waktu, $t=$ waktu yang dipilih, $C_{v}=$ koefisien konsolidasi dan $H d r=$ jarak air pori di lapisan tanah untuk mengalir keluar

Harga $U_{v}$ dapat dicari dengan rumus:

Untuk $U_{v}$ antara $0 \mathrm{~s} / \mathrm{d} 60 \%$

$$
U_{v}=\left(2 \sqrt{\frac{T_{v}}{\pi}}\right) 100 \%
$$

Untuk Uv antara $60 \%$ s/d $100 \%$

$$
U=\left(100-10^{a}\right) \%
$$

dengan $U_{v}=$ derajat konsolidasi arah vertical, $T_{v}=$ faktor waktu arah vertical dan $a=(1.781-T) / 0.933$

Derajat konsolidasi rata-rata $\mathrm{U}$ dapat dicari dengan cara:

$$
U=\left[1-\left(1-U_{h}\right)\left(1-U_{v}\right)\right] \%
$$

Uh dicari menggunakan persamaan:

$$
U_{h}=\left[1-\left(1 / e^{\left(\frac{t \times 8 \times C_{h}}{d_{e}^{2} \times F(n)}\right)}\right)\right] \%
$$

dengan $U=$ derajat konsolidasi total, $U_{v}=$ derajat konsolidasi arah vertical, $U_{h}=$ derajat konsolidasi arah horizontal, $e=$ bilangan natural, $t=$ waktu konsolidasi, $C_{h}=$ koefisien konsolidasi arah horizontal, $d_{e}=$ diameter ekivalen dari lingkaran tanah pengaruh PVD dan $F(n)=$ faktor hambatan disebabkan karena jarak antar PVD

\section{METODOLOGI PENELITIAN}

\section{Kerangka berpikir}

Seluruh langkah kerja yang akan dilakukan dalam penelitian ini dapat dilihat melalui kerangka berpikir yang dapat dilihat melalui Gambar 4. 


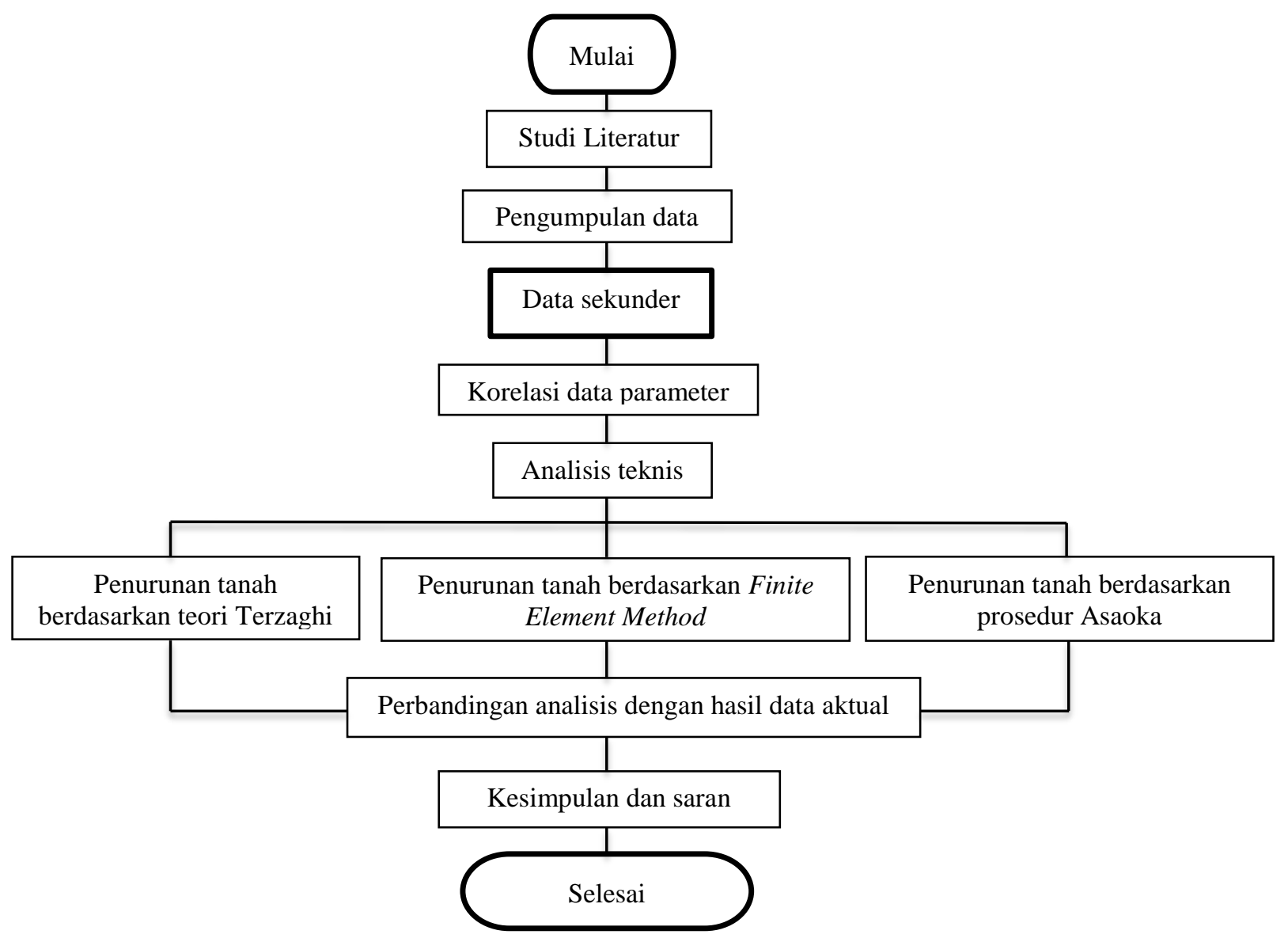

Gambar 4. Diagram Alir Pengerjaan Tugas Akhir

\section{HASIL DAN PEMBAHASAN}

Tabel 3. Rekapitulasi Data Parameter Tanah Dasar

\begin{tabular}{cccccccc}
\hline Kedalaman $(m)$ & $0-2$ & $2-4$ & $4-6$ & $6-8$ & $8-11$ & $11-12$ & $12-15$ \\
\hline NSPT & 5 & 7 & 11 & 9 & 9 & 14 & 17 \\
\hline$\gamma s a t\left(k N / m^{3}\right)$ & 16.38 & $\mathbf{1 9 . 2 5}$ & 18.38 & $\mathbf{1 9 . 4 3}$ & 15.27 & $\mathbf{2 1 . 5 7}$ & 16.41 \\
\hline$\gamma d\left(k N / m^{3}\right)$ & 9.90 & $\mathbf{1 7 . 7 9}$ & 12.84 & $\mathbf{1 8 . 0 0}$ & 8.23 & $\mathbf{2 0 . 5 0}$ & 10.00 \\
\hline$\gamma b\left(k N / m^{3}\right)$ & $\mathbf{1 5 . 7 8}$ & $\mathbf{1 8 . 9 1}$ & $\mathbf{1 7 . 7 4}$ & $\mathbf{1 9 . 0 9}$ & $\mathbf{1 4 . 6 0}$ & $\mathbf{2 0 . 8 1}$ & $\mathbf{1 5 . 4 8}$ \\
\hline$e$ & 1.68 & $\mathbf{0 . 8 2}$ & 1.10 & $\mathbf{0 . 7 9}$ & 2.17 & $\mathbf{0 . 4 7}$ & 1.62 \\
\hline$C_{c}$ & $\mathbf{0 . 5 0}$ & $\mathbf{0 . 4 8}$ & $\mathbf{0 . 6 0}$ & $\mathbf{0 . 3 9}$ & $\mathbf{0 . 5 9}$ & $\mathbf{0 . 3 9}$ & $\mathbf{0 . 4 7}$ \\
\hline$C_{s}$ & $\mathbf{0 . 1 0}$ & $\mathbf{0 . 1 0}$ & $\mathbf{0 . 1 2}$ & $\mathbf{0 . 0 8}$ & $\mathbf{0 . 1 2}$ & $\mathbf{0 . 0 8}$ & $\mathbf{0 . 0 9}$ \\
\hline$C_{v}\left(c m^{2} / s\right)$ & $\mathbf{5 . 1 3 E - 0 4}$ & $\mathbf{9 . 7 5 E - 0 4}$ & $\mathbf{8 . 3 0 E - 0 4}$ & $\mathbf{1 . 1 4 E - 0 3}$ & $\mathbf{2 . 3 4 E - 0 4}$ & $\mathbf{1 . 0 0 E - 0 3}$ & $\mathbf{5 . 1 8 E - 0 4}$ \\
\hline$K(c m / s)$ & $\mathbf{1 . 1 3 E - 0 6}$ & $\mathbf{5 . 7 5 E - 0 6}$ & $\mathbf{4 . 3 0 E - 0 6}$ & $\mathbf{6 . 0 3 E - 0 6}$ & $\mathbf{7 . 0 2 E - 0 8}$ & $\mathbf{9 . 3 9 E - 0 6}$ & $\mathbf{1 . 1 8 E - 0 6}$ \\
\hline $\mathrm{Su}\left(k N / m^{2}\right)$ & $\mathbf{3 0}$ & $\mathbf{4 2}$ & 74 & $\mathbf{5 4}$ & $\mathbf{5 4}$ & $\mathbf{8 4}$ & $\mathbf{1 0 2}$ \\
\hline$\phi\left({ }^{\circ}\right)$ & $\mathbf{2 7}$ & $\mathbf{2 6}$ & $\mathbf{2 4}$ & $\mathbf{2 7}$ & $\mathbf{2 8}$ & $\mathbf{2 4}$ & $\mathbf{2 6}$ \\
\hline$E$ & $\mathbf{5 4 0 0}$ & $\mathbf{7 5 6 0}$ & $\mathbf{1 3 3 2 0}$ & $\mathbf{9 7 2 0}$ & $\mathbf{9 7 2 0}$ & $\mathbf{1 5 1 2 0}$ & $\mathbf{1 8 3 6 0}$ \\
\hline$v$ & $\mathbf{0 . 2}$ & $\mathbf{0 . 2}$ & $\mathbf{0 . 2}$ & $\mathbf{0 . 2}$ & $\mathbf{0 . 2}$ & $\mathbf{0 . 2}$ & $\mathbf{0 . 2}$ \\
\hline
\end{tabular}

Catatan: Data yang ditebalkan merupakan data hasil korelasi 


\section{Analisis penurunan metode Terzaghi}

Perhitungan penurunan konsolidasi primer ditinjau pada setiap kedalaman dengan interval $1 \mathrm{~m}$. Berikut adalah tabel perhitungan penurunan untuk kedalaman per $1 \mathrm{~m}$.

Tabel 4. Perhitungan Penurunan Konsolidasi Primer

\begin{tabular}{|c|c|c|c|c|c|c|c|c|}
\hline Kedalaman $(m)$ & $H(m)$ & $e$ & $C_{c}$ & $\overline{C_{s}}$ & $\sigma_{o}{ }^{\prime}\left(t / m^{2}\right)$ & $\Delta \sigma\left(t / m^{2}\right)$ & $\sigma_{c}^{\prime}\left(t / m^{2}\right)$ & $S c(m)$ \\
\hline $0-1$ & 1 & 1.68 & 0.50 & 0.10 & 7.5779 & 6.4089 & 15.7938 & 0.0100 \\
\hline $1-2$ & 1 & 1.68 & 0.50 & 0.10 & 9.1557 & 6.1188 & 15.0643 & 0.0092 \\
\hline $2-2.75$ & 0.75 & 0.82 & 0.48 & 0.10 & 10.6427 & 5.8705 & 22.0938 & 0.0076 \\
\hline $2.75-3$ & 0.25 & 0.82 & 0.48 & 0.10 & 11.4564 & 5.7840 & 21.6906 & 0.0024 \\
\hline $3-4$ & 1 & 0.82 & 0.48 & 0.10 & 12.0345 & 5.4290 & 21.4253 & 0.0086 \\
\hline $4-5$ & 1 & 1.10 & 0.60 & 0.12 & 12.9160 & 5.0734 & 42.7296 & 0.0082 \\
\hline $5-6$ & 1 & 1.10 & 0.60 & 0.12 & 13.7541 & 4.7311 & 42.0633 & 0.0073 \\
\hline $6-7$ & 1 & 0.79 & 0.39 & 0.08 & 14.6447 & 4.4102 & 27.9283 & 0.0050 \\
\hline $7-8$ & 1 & 0.79 & 0.39 & 0.08 & 15.5877 & 4.1145 & 27.4959 & 0.0044 \\
\hline $8-9$ & 1 & 2.17 & 0.59 & 0.12 & 16.3226 & 3.8448 & 27.1811 & 0.0034 \\
\hline $9-10$ & 1 & 2.17 & 0.59 & 0.12 & 16.8494 & 3.6004 & 26.9661 & 0.0031 \\
\hline $10-11$ & 1 & 2.17 & 0.59 & 0.12 & 17.3762 & 3.3794 & 26.7593 & 0.0029 \\
\hline $11-12$ & 1 & 0.47 & 0.39 & 0.08 & 18.2181 & 3.1798 & 45.9404 & 0.0037 \\
\hline $12-13$ & 1 & 1.62 & 0.47 & 0.09 & 19.1172 & 2.9994 & 57.8583 & 0.0023 \\
\hline $13-14$ & 1 & 1.62 & 0.47 & 0.09 & 19.7585 & 2.8360 & 57.3831 & 0.0021 \\
\hline $14-15$ & 1 & 1.62 & 0.47 & 0.09 & 20.3997 & 2.6878 & 56.9267 & 0.0019 \\
\hline \multicolumn{8}{|c|}{ Penurunan = } & 0.0821 \\
\hline
\end{tabular}

Tabel 5. Perhitungan Waktu Penurunan Konsolidasi Menggunakan PVD Perhitungan Penurunan (PVD)

\begin{tabular}{cccccccc}
\hline$t$ (hari) & $C_{h}\left(m^{2} /\right.$ tahun $)$ & $T v$ & $U v$ & $T r$ & $U r$ & $U$ & $S c(m)$ \\
\hline 10 & 2.3472 & 0.0005 & 0.026 & 0.0583 & 0.1837 & 0.2049 & 0.0168 \\
\hline 20 & 2.3472 & 0.0011 & 0.0368 & 0.1167 & 0.3336 & 0.3581 & 0.0294 \\
\hline 40 & 2.3472 & 0.0021 & 0.052 & 0.2333 & 0.5559 & 0.579 & 0.0476 \\
\hline 60 & 2.3472 & 0.0032 & 0.0637 & 0.35 & 0.704 & 0.7229 & 0.0594 \\
\hline 80 & 2.3472 & 0.0043 & 0.0736 & 0.4666 & 0.8028 & 0.8173 & 0.0671 \\
\hline 100 & 2.3472 & 0.0053 & 0.0823 & 0.5833 & 0.8686 & 0.8794 & 0.0722 \\
\hline 130 & 2.3472 & 0.0069 & 0.0938 & 0.7583 & 0.9285 & 0.9352 & 0.0768 \\
\hline 170 & 2.3472 & 0.0090 & 0.1073 & 0.9916 & 0.9682 & 0.9717 & 0.0797 \\
\hline 190 & 2.3472 & 0.0101 & 0.1134 & 1.1082 & 0.9788 & 0.9812 & 0.0805 \\
\hline 220 & 2.3472 & 0.0117 & 0.1220 & 1.2832 & 0.9885 & 0.9899 & 0.0812 \\
\hline 240 & 2.3472 & 0.0128 & 0.1275 & 1.3999 & 0.9923 & 0.9933 & 0.0815 \\
\hline 260 & 2.3472 & 0.0138 & 0.1327 & 1.5165 & 0.9949 & 0.9956 & 0.0817 \\
\hline
\end{tabular}

\section{Analisis penurunan finite element method (FEM)}

Pada Analisis penurunan finite element method akan diolah parameter tanah dasar dan timbunan: 
Studi Kasus Perbandingan Analisis Penurunan Akibat Timbunan, di Tangerang, Banten

Fachry Ibrahim, et al.

Tabel 6. Parameter Input Tanah Timbunan

\begin{tabular}{cccc}
\hline & \multicolumn{3}{c}{ Parameter Tanah Timbunan } \\
\hline Jenis tanah & Preloading & Control Fill & Sand Blanket \\
\hline Tipe & Drained & Drained & Undrained \\
\hline$\gamma_{\text {sat }}\left(\mathrm{kN} / \mathrm{m}^{3}\right)$ & 17 & 20 & 20 \\
\hline$\gamma_{\text {unsat }}\left(\mathrm{kN} / \mathrm{m}^{3}\right)$ & 13 & 17 & 17 \\
\hline$C\left(\mathrm{kN} / \mathrm{m}^{2}\right)$ & 30 & 30 & 0.1 \\
\hline$\phi\left({ }^{\circ}\right)$ & 15 & 15 & 35 \\
\hline$E\left(\mathrm{kN} / \mathrm{m}^{2}\right)$ & 10000 & 40000 & 25000 \\
\hline$K x(\mathrm{~m} / \mathrm{hari})$ & $1.00 \mathrm{E}-05$ & $1.00 \mathrm{E}-05$ & $1.00 \mathrm{E}-03$ \\
\hline$K y(\mathrm{~m} / \mathrm{hari})$ & $1.00 \mathrm{E}-05$ & $1.00 \mathrm{E}-05$ & $1.00 \mathrm{E}-03$ \\
\hline Poisson's Ratio & 0.3 & 0.3 & 0.3 \\
\hline
\end{tabular}

Tabel 7. Parameter Input Tanah Dasar

\begin{tabular}{|c|c|c|c|c|c|c|c|}
\hline \multirow[b]{2}{*}{$\begin{array}{c}\text { Lapisan } \\
\text { (m) }\end{array}$} & \multicolumn{7}{|c|}{ Parameter Tanah Dasar } \\
\hline & $0-2$ & $2-4$ & $4-6$ & $6-8$ & $8-11$ & $11-12$ & $12-15$ \\
\hline Jenis tanah & Elastic Silt with Sand & Elastic Silt with Sand & Fat Clay & Fat Clay & Fat Clay & Fat Clay & Fat Clay \\
\hline Tipe & Undrained & Undrained & Undrained & Undrained & Undrained & Undrained & Undrained \\
\hline$N-S P T$ & 5 & 7 & 11 & 9 & 9 & 14 & 17 \\
\hline$\gamma_{\text {sat }}\left(k N / m^{3}\right)$ & 16.38 & 19.25 & 18.38 & 19.43 & 15.27 & 21.57 & 16.41 \\
\hline$\gamma_{\text {unsat }}\left(k N / m^{3}\right)$ & 15.78 & 18.91 & 17.74 & 19.09 & 14.60 & 20.81 & 15.48 \\
\hline$C\left(k N / m^{2}\right)$ & 30 & 42 & 66 & 54 & 54 & 84 & 102 \\
\hline$\phi\left(^{\circ}\right)$ & 27 & 26 & 24 & 27 & 28 & 24 & 26 \\
\hline$E\left(k N / m^{2}\right)$ & 5400 & 7560 & 13320 & 9720 & 9720 & 15120 & 18360 \\
\hline$K x($ m/hari $)$ & $9.76 \mathrm{E}-04$ & $4.97 \mathrm{E}-03$ & $3.72 \mathrm{E}-03$ & $5.21 \mathrm{E}-03$ & $6.07 \mathrm{E}-05$ & $8.11 \mathrm{E}-03$ & $1.02 \mathrm{E}-03$ \\
\hline Ky (m/hari $)$ & $9.76 \mathrm{E}-04$ & $4.97 \mathrm{E}-03$ & $3.72 \mathrm{E}-03$ & $5.21 \mathrm{E}-03$ & $6.07 \mathrm{E}-05$ & $8.11 \mathrm{E}-03$ & $1.02 \mathrm{E}-03$ \\
\hline Poisson's Ratio & 0.2 & 0.2 & 0.2 & 0.2 & 0.2 & 0.2 & 0.2 \\
\hline
\end{tabular}

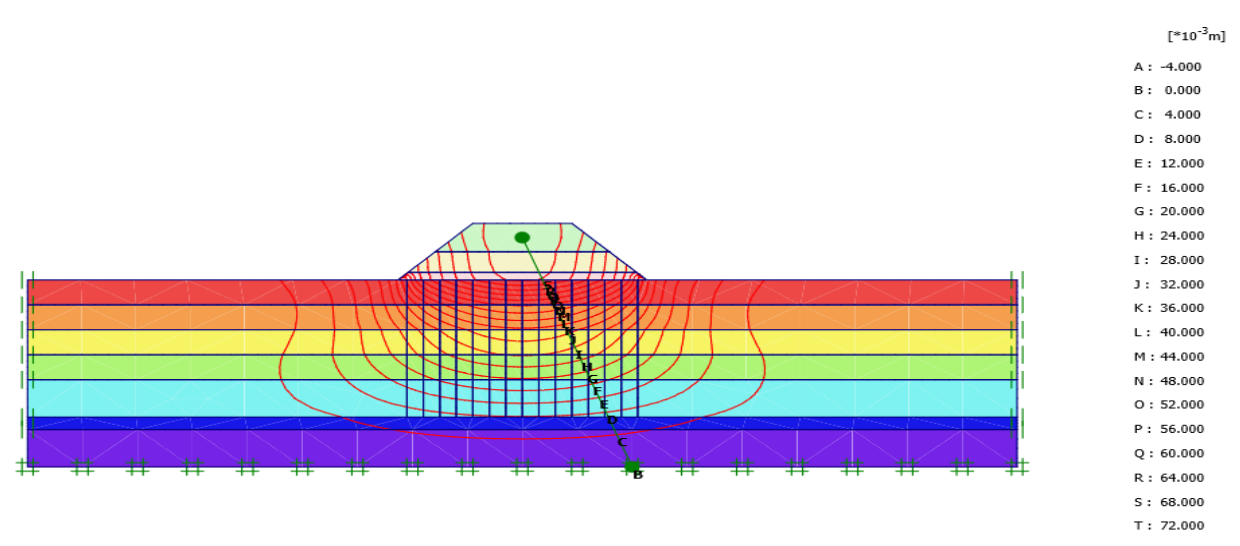

Total displacements (Utot)
Extreme Utot $71.24^{*} 10^{-3} \mathrm{~m}$

Gambar 5. Konsolidasi Total Finite Element Method (FEM) 


\section{Analisis penurunan metode Asaoka}

Analisis dengan plot grafik antara penurunan pada waktu $n\left(\rho_{n}\right)$ pada sumbu-y dan penurunan pada waktu $n-1$ $\left(\rho_{n-1}\right)$ pada sumbu $x$. Perpotongan trendline linier dari titik plot grafik dengan garis $\rho_{n}=\rho_{n-1}$ merupakan penurunan akhir $(h f)$ timbunan dapat dilihat pada Gambar 6.

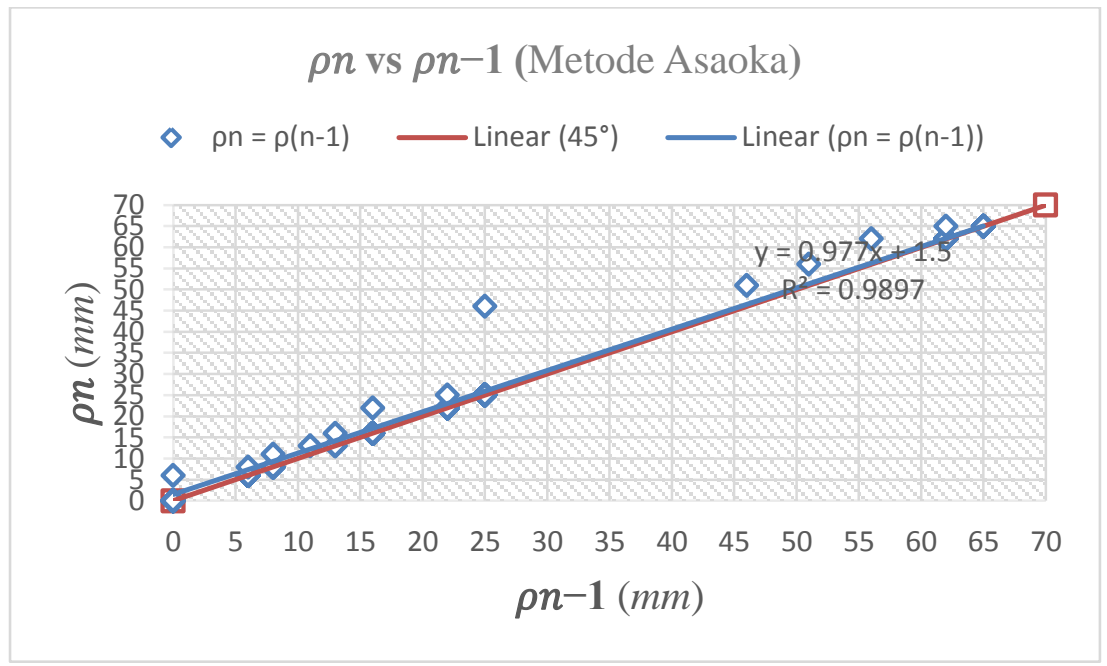

Gambar 6. Grafik on vs ( $\rho n-1)$ Metode Asaoka

Tabel 8. Perhitungan Waktu Penurunan Konsolidasi menggunakan PVD

\begin{tabular}{cccccccc}
\hline \multicolumn{7}{c}{ Perhitungan Waktu Penurunan Kombinasi (PVD) } \\
\hline$t$ (hari) & $C_{h}\left(\mathrm{~m}^{2} /\right.$ tahun $)$ & $T_{v}$ & $U_{v}$ & $T_{r}$ & $U_{r}$ & $U$ & $S_{c}(\mathrm{~m})$ \\
\hline 30 & 3.5775 & 0.0008 & 0.0321 & 0.2667 & 0.6046 & 0.6173 & 0.04040 \\
\hline 60 & 3.5775 & 0.0016 & 0.0454 & 0.5334 & 0.8437 & 0.8508 & 0.05568 \\
\hline 90 & 3.5775 & 0.0024 & 0.0556 & 0.8001 & 0.9382 & 0.9416 & 0.06163 \\
\hline 120 & 3.5775 & 0.0032 & 0.0642 & 1.0668 & 0.9756 & 0.9771 & 0.06395 \\
\hline 160 & 3.5775 & 0.0043 & 0.0742 & 1.4224 & 0.9929 & 0.9934 & 0.06502 \\
\hline 180 & 3.5775 & 0.0049 & 0.0787 & 1.6002 & 0.9962 & 0.9965 & 0.06522 \\
\hline
\end{tabular}

\section{KESIMPULAN DAN SARAN}

\section{Kesimpulan}

1. Hasil penurunan dari metode Asaoka adalah hasil penurunan yang paling mendekati hasil aktual. Hasil perhitungan penurunan dan waktu dari ketiga metode dengan hasil aktual dilapangan pada Tabel 9 dan Gambar 7.

Tabel 9. Hasil Penurunan Konsolidasi Analisis dan Aktual

\begin{tabular}{cccc}
\hline \multicolumn{4}{c}{ Penurunan Konsolidasi Primer $(\mathrm{mm})$} \\
\hline SP-08 & Terzaghi & FEM & Asaoka \\
\hline 65 & 82.10 & 71.24 & 65.22 \\
\hline
\end{tabular}


Tabel 10. Hasil Waktu Penurunan Konsolidasi Analisis dan Aktual

\begin{tabular}{cccc}
\hline \multicolumn{4}{c}{ Waktu Penurunan Konsolidasi Primer (hari) } \\
\hline SP-08 & Terzaghi & FEM & Asaoka \\
\hline 155 & 260 & 160 & 180
\end{tabular}

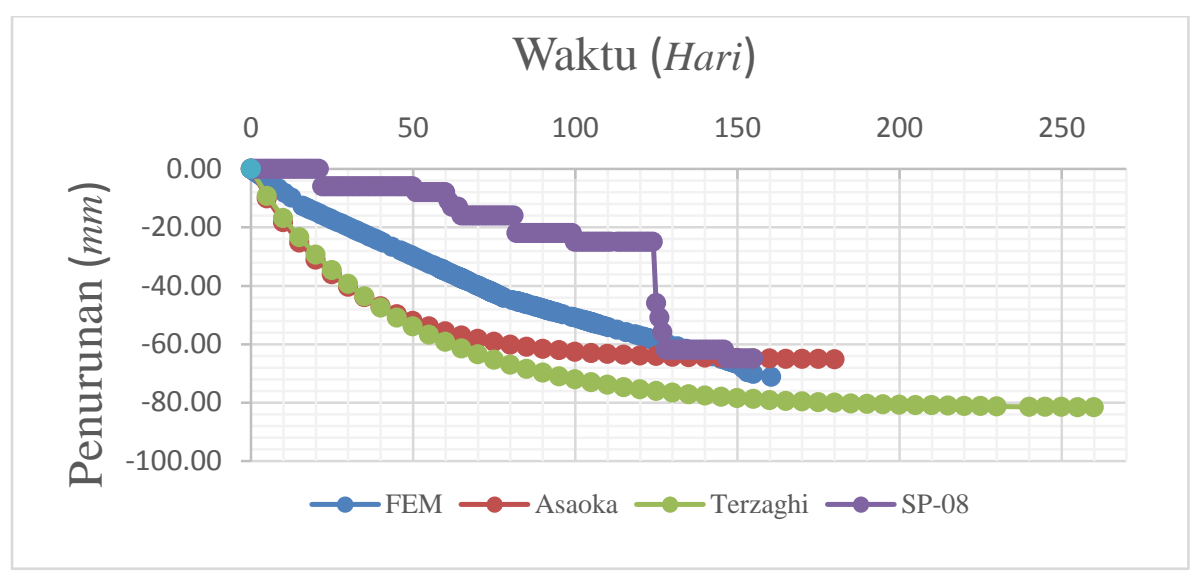

Gambar 7. Grafik Perbandingan Penurunan vs Waktu

2. Estimasi hasil dari metode Asaoka dapat diperoleh nilai penurunan akhir yang lebih mendekati penurunan aktual lapangan dengan perbedaan $0.34 \%$ pada Gambar 8 .

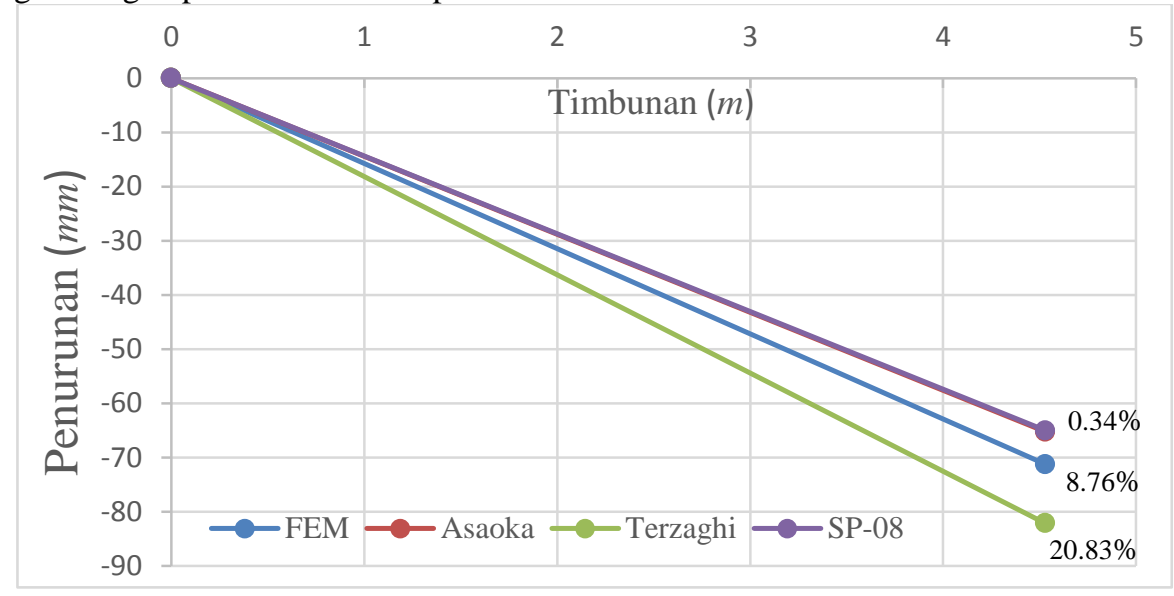

Gambar 8. Grafik Perbandingan \% Penurunan

\section{DAFTAR PUSTAKA}

Asaoka, A. (1978). Observational Procedure of Settlement Prediction. Japanese Geotechnical Society, Tokyo. Bowles, J.E. (1984). Physical and Geotechnical Properties of Soils. McGraw-Hill Book Company, New York. Barron, R. A. (1948). Consolidation of Fine-Grained Soils by Drain Wells. Transactions of ASCE, Vol. 113.

Das, Braja M. (1985). Mekanika Tanah (Prinsip-Prinsip Rekayasa Geoteknik). Erlangga, Jakarta.

Lambe, W. (1969). Soil Mechanics. John Willey \& Sons, New York.

Magnan J.P. and Deroy J.M. (1980). “Analyse Graphique Des Tassements Observes Sous Les Ouvrage”s. Bull. Liaison Labo. P.\&Ch, Sept-Okt 1980, 109.

Mikasa, M. (1963). Consolidation of Soft Clay. Kajimashuppan-kai, Tokyo.

Terzaghi, K. (1943). Theoritical Soil Mechanics. John Willey \& Sons, New York. 